\title{
High-temperature order-disorder transitions in the skutterudites CoGe1.5Q1.5 (Q=S, Te)
}

Article

Accepted Version

Kaltzoglou, A., Powell, A., Knight, K. S. and Vaqueiro, P. (2013) High-temperature order-disorder transitions in the skutterudites CoGe1.5Q1.5 (Q=S, Te). Journal of Solid State Chemistry, 198. pp. 525-531. ISSN 0022-4596 doi: https://doi.org/10.1016/j.jssc.2012.11.025 Available at https://centaur.reading.ac.uk/39887/

It is advisable to refer to the publisher's version if you intend to cite from the work. See Guidance on citing.

To link to this article DOI: http://dx.doi.org/10.1016/j.jssc.2012.11.025

Publisher: Elservier

All outputs in CentAUR are protected by Intellectual Property Rights law, including copyright law. Copyright and IPR is retained by the creators or other copyright holders. Terms and conditions for use of this material are defined in the End User Agreement.

www.reading.ac.uk/centaur 
Central Archive at the University of Reading

Reading's research outputs online 


\title{
High-Temperature Order-Disorder Transitions in the Skutterudites
}

$$
\mathrm{CoGe}_{1.5} \mathbf{Q}_{1.5}(\mathrm{Q}=\mathrm{S}, \mathrm{Te})
$$

\author{
Andreas Kaltzoglou ${ }^{\mathrm{a}}$, Anthony V. Powell ${ }^{\mathrm{a}}$, Kevin S. Knight ${ }^{\mathrm{b}}$, Paz Vaqueiro ${ }^{\mathrm{a}, *}$ \\ ${ }^{a}$ Institute of Chemical Sciences \& Centre for Advanced Energy Storage and Recovery \\ (CAESAR), Heriot-Watt University, Edinburgh EH14 4AS, UK \\ ${ }^{\mathrm{b}}$ ISIS Facility, Rutherford Appleton Laboratory, Didcot, Oxfordshire OX11 0OX, UK
}

*Author for correspondence:

Dr P. Vaqueiro

Institute of Chemical Sciences

Heriot-Watt University

Edinburgh EH14 4AS

UK

Fax: +44(0)1314513180

E-mail: chepv@hw.ac.uk 


\begin{abstract}
The temperature dependence of anion ordering in the skutterudites $\operatorname{CoGe}_{1.5} \mathrm{Q}_{1.5}(\mathrm{Q}=\mathrm{S}, \mathrm{Te})$ has been investigated by powder neutron diffraction. Both materials adopt a rhombohedral structure at room temperature (space group $R \overline{3}$ ) in which the anions are ordered trans to each other within $\mathrm{Ge}_{2} \mathrm{Q}_{2}$ rings. In $\mathrm{CoGe}_{1.5} \mathrm{~S}_{1.5}$, anion ordering is preserved up to the melting point of $950{ }^{\circ} \mathrm{C}$. However, rhombohedral $\mathrm{CoGe}_{1.5} \mathrm{Te}_{1.5}$ undergoes a phase transition at $610{ }^{\circ} \mathrm{C}$ involving a change to cubic symmetry (space group $\operatorname{Im} \overline{3}$ ). In the high-temperature modification, there is a statistical distribution of anions over the available sites within the $\mathrm{Ge}_{2} \mathrm{Te}_{2}$ rings. The structural transition involves a reduction in the degree of distortion of the $\mathrm{Ge}_{2} \mathrm{Te}_{2}$ rings which progressively transform from a rhombus to a rectangular shape. The effect of this transition on the thermoelectric properties has been investigated.
\end{abstract}

Keywords: Skutterudites; anion ordering; thermoelectric properties 


\section{Introduction}

The use of thermoelectric materials in devices for cooling and energy recovery applications is attracting increasing interest. Several classes of compounds have been studied with respect to their thermoelectric properties, including skutterudites, which are particularly promising for high-temperature applications [1,2]. Binary skutterudites (Figure 1) consist of a three-dimensional array of tilted and vertex-linked metal centred $\mathrm{MX}_{6}$ octahedra (where $\mathrm{M}=$ $\mathrm{Co}, \mathrm{Rh}, \mathrm{Ir}$ and $\mathrm{X}=\mathrm{P}, \mathrm{As}, \mathrm{Sb}$ ), resulting in a framework of stoichiometry $\mathrm{MX}_{3}$ (space group $\operatorname{Im} \overline{3}$ ) [3]. Tilting of the octahedra leads to the formation of rectangular four-membered anion rings, which are a characteristic feature of skutterudites. In addition, the skutterudite structure (Figure 1) contains large voids, which can be filled to varying degrees by electropositive atoms giving rise to filled skutterudites of general formula, $R_{x} M_{4} X_{12}$ (where $R$ may be a rareearth, alkali metal, alkaline earth or group 13 element) [4,5]. Whilst the thermal conductivity of unfilled binary skutterudites is too high for thermoelectric applications, low thermal conductivities are found upon insertion of filler atoms [5].

Isoelectronic substitution at the anion site in binary skutterudites results in a family of ternary phases with the general formula $\mathrm{AB}_{1.5} \mathrm{Q}_{1.5}(\mathrm{~A}=\mathrm{Co}, \mathrm{Rh}, \mathrm{Ir} ; \mathrm{B}=\mathrm{Ge}, \mathrm{Sn} ; \mathrm{Q}=\mathrm{S}, \mathrm{Se}, \mathrm{Te})$ $[6,7,8,9,10,11,12,13,14,15]$. The existence of the first members of this family, $\mathrm{CoGe}_{1.5} \mathrm{Q}_{1.5}(\mathrm{Q}$ $=\mathrm{S}, \mathrm{Se}$ ), was described by Korenstein et al [6], and was shortly followed by the discovery of $\mathrm{RhGe}_{1.5} \mathrm{~S}_{1.5}, \mathrm{IrGe}_{1.5} \mathrm{Q}_{1.5}(\mathrm{Q}=\mathrm{S}, \mathrm{Se})$ and $\mathrm{IrSn}_{1.5} \mathrm{~S}_{1.5}$ [7]. These reports suggested that the mixedanion phases crystallise in the non-centrosymmetric space group $R 3$, due to the presence of short-range anion ordering. However, a detailed structural study on $\mathrm{CoGe}_{1.5} \mathrm{Te}_{1.5}$ using powder neutron diffraction demonstrated that this phase is centrosymmetric (space group $R \overline{3}$ ), and that the anions exhibit long-range ordering within two-crystallographically distinct $\mathrm{Ge}_{2} \mathrm{Te}_{2}$ rings, in which the $\mathrm{Ge}$ and $\mathrm{Te}$ atoms are trans to each other (Figure 2) [9]. The majority of the known $\mathrm{AB}_{1.5} \mathrm{Q}_{1.5}$ phases are isostructural with $\mathrm{CoGe}_{1.5} \mathrm{Te}_{1.5}$ and crystallise in the space group $R \overline{3}[10,11,12,13,14]$. However, both disordered cubic and ordered 
rhombohedral structures have been proposed for $\mathrm{CoGe}_{1.5} \mathrm{Se}_{1.5}$ and $\mathrm{CoSn}_{1.5} \mathrm{Te}_{1.5},[8,16,11,17]$ whilst $\operatorname{IrGe}_{1.5} \mathrm{Te}_{1.5}$ appears to adopt a cubic skutterudite structure [14]. In ternary phases, anion ordering is often incomplete; the degree of ordering decreasing with increasing size of both cations and anions [14]. Complete or partial anion ordering has been found to have a marked effect on the thermoelectric properties of these materials, which exhibit significantly lower thermal conductivities and higher electrical resistivities than their binary counterparts $[9,12,13,15,18,19]$. The higher electrical resistivity has been attributed to the increased ionicity within the four-membered anion rings, whilst recent calculations of phonon dispersion curves [20] suggest that the reduced thermal conductivity may be related to changes in the phonon scattering mechanism due to the different nature of the bonding in the mixed-anion phases.

Here, we focus on an investigation of the effect of temperature on anion ordering in the ternary skutterudites $\mathrm{CoGe}_{1.5} \mathrm{Q}_{1.5}(\mathrm{Q}=\mathrm{S}, \mathrm{Te})$, using time-of-flight powder neutron diffraction. This study is motivated by our previous synthetic work, which suggests that the degree of ordering may be dependent on the rate of cooling during sample preparation. We describe the structural changes occurring in the title compounds at elevated temperatures and discuss their potential effects on the thermoelectric properties of these materials.

\section{Experimental}

$\mathrm{CoGe}_{1.5} \mathrm{~S}_{1.5}$ and $\mathrm{CoGe}_{1.5} \mathrm{Te}_{1.5}$ were prepared from stoichiometric mixtures of the elements Co (Aldrich, 99.9\%), Ge (Alfa-Aesar, 99.999\%), S (Aldrich, 99.998\%) and Te (Aldrich, 99.99\%). Ge powder was reduced prior to use by heating to $500{ }^{\circ} \mathrm{C}$ for 3 hours under a flow of 5\% hydrogen in argon. All other components were used as received. The reagents were mixed in an argon-filled glovebox before being loaded into fused silica tubes. The tubes were closed, transferred to a vacuum line and evacuated to $<10^{-4}$ Torr prior to sealing. For $\mathrm{CoGe}_{1.5} \mathrm{~S}_{1.5}$ the mixture was heated at $600{ }^{\circ} \mathrm{C}$ for 4 days. After cooling at a rate of 
$1{ }^{\circ} \mathrm{C} \min ^{-1}$, the product was finely ground in air and refired at $700{ }^{\circ} \mathrm{C}$ for 4 days. For $\mathrm{CoGe}_{1.5} \mathrm{Te}_{1.5}$, the mixture was initially heated for 24 hours at $500{ }^{\circ} \mathrm{C}$ followed by a period of 4 days at $600{ }^{\circ} \mathrm{C}$. The tube was cooled at a rate of $1{ }^{\circ} \mathrm{C} \min ^{-1}$ and opened in air. The solid product was finely ground in air before annealing in an evacuated silica tube at $600{ }^{\circ} \mathrm{C}$ for 4 days. The annealing process was repeated two further times in order to produce essentially phase pure products.

The air-stable polycrystalline products were structurally characterised using a Bruker D8 Advance powder diffractometer, operating with Ge-monochromated $\mathrm{Cu} K_{\alpha 1}$ radiation $(\lambda=$ $1.5406 \AA$ ) and a LynxEye linear detector. Data were collected over the angular range $10 \leq$ $2 \theta /^{\circ} \leq 120$ counting for $3 \mathrm{~s}$ and $2.1 \mathrm{~s}$ for $\mathrm{CoGe}_{1.5} \mathrm{~S}_{1.5}$ and $\mathrm{CoGe}_{1.5} \mathrm{Te}_{1.5}$, respectively at each step of $0.0092^{\circ}$ in detector position. Time-of-flight powder neutron diffraction data were collected using the HRPD diffractometer at the ISIS Facility, Rutherford Appleton Laboratory, UK. Powdered samples of each material were sealed into evacuated low-boron content silica ampoules. The ampoule was contained in a thin-walled vanadium can held in a furnace evacuated to a pressure $<10^{-4}$ Torr. Data were collected over the temperature range $25 \leq \mathrm{T} /{ }^{\circ} \mathrm{C}$ $\leq 950$ for $\mathrm{CoGe}_{1.5} \mathrm{~S}_{1.5}$ and $25 \leq \mathrm{T} /{ }^{\circ} \mathrm{C} \leq 665$ for $\mathrm{CoGe}_{1.5} \mathrm{Te}_{1.5}$. Initial data manipulation and reduction was carried out using the Mantid [21] software package. Neutron diffraction data from the backscattering $\left(168^{\circ}\right)$ and $90^{\circ}$ detector banks were summed, normalised and used simultaneously in Rietveld refinement, carried out using the GSAS package [22].

Samples for thermoelectric measurements were fabricated by hot pressing. Approximately, $2 \mathrm{~g}$ of sample was placed in a $13 \mathrm{~mm}$ diameter graphite die which was heated to $620^{\circ} \mathrm{C}$ for 30 minutes in a nitrogen atmosphere under a pressure of $600 \mathrm{bar}$. The resulting pellets have a density ca. $95 \%$ of the crystallographic density. Powder X-ray diffraction data collected after hot pressing confirms that the pellet consists of rhombohedral $\mathrm{CoGe}_{1.5} \mathrm{Te}_{1.5} . \mathrm{A}$ rectangular block with approximate dimensions of $2 \times 2 \times 10 \mathrm{~mm}^{3}$ was cut from a pellet with a low-speed diamond saw (MTI Corporation, SYJ-150) and polished with fine sandpaper. 
Electrical resistivity and Seebeck coefficient measurements over the temperature range $30 \leq$ $T /{ }^{\circ} \mathrm{C} \leq 650$ were performed simultaneously on the rectangular block using a Linseis LSR-3 instrument under a static $\mathrm{He}$ atmosphere (pressure $1.1-1.4$ bar). Thermal diffusivity measurements were carried out on $2 \mathrm{~mm}$ thick, $13 \mathrm{~mm}$ diameter hot-pressed pellets over the temperature range $100 \leq T /{ }^{\circ} \mathrm{C} \leq 650$ using an Anter Flashline 3000 instrument. This instrument determines both the thermal diffusivity $(\alpha)$ and the heat capacity $\left(\mathrm{C}_{p}\right)$ of the sample, and the thermal conductivity $(\kappa)$ is calculated from the relationship: $\kappa=\alpha \mathrm{C}_{p} \rho$, where $\rho$ is the sample density. For the determination of the heat capacity, a reference material, PyroceramTM 9606, of known heat capacity was used, as described in detail in refs. 23 and 24.

The thermal stability of $\mathrm{CoGe}_{1.5} \mathrm{Te}_{1.5}$ at elevated temperatures was investigated with a DuPont 951 thermogravimetric analyser (TGA). The sample (ca. $30 \mathrm{mg}$ ) was loaded into a silica crucible and heated at a rate of $5{ }^{\circ} \mathrm{C} \min ^{-1}$ to $635^{\circ} \mathrm{C}$ under a $120 \mathrm{~mL} \mathrm{~min}^{-1}$ flow of pure nitrogen.

\section{Results and discussion}

Laboratory powder X-ray diffraction data for $\mathrm{CoGe}_{1.5} \mathrm{Q}_{1.5}(\mathrm{Q}=\mathrm{S}, \mathrm{Te})$ may be indexed on the basis of a cubic unit cell, consistent with the archetypal skutterudite structure. The powder X-ray diffraction data for $\mathrm{CoGe}_{1.5} \mathrm{Te}_{1.5}$ (Supplementary Information) indicate the presence of low levels of GeTe (3.5(1) wt $\%$ ) and $\mathrm{GeO}_{2}(6.8(3) \mathrm{wt} \%)$ impurities. The powder neutron diffraction data for $\operatorname{CoGe}_{1.5} \mathrm{Q}_{1.5}(\mathrm{Q}=\mathrm{S}$, Te $)$ contain a number of additional reflections, the strongest of which occur at d-spacings of 2.674 and $1.903 \AA$ for $\mathrm{Q}=\mathrm{S}$ and $\mathrm{Te}$ respectively. We have previously shown [9] that these are superstructure reflections, consistent with a reduction in symmetry to the centrosymmetric space group $R \overline{3}$. Rietveld refinement was therefore initiated in space group $R \overline{3}$ using atomic coordinates determined in our earlier study [9] for the initial structural model. For each material, a single isotropic 
thermal displacement parameter $\left(U_{\text {iso }}\right)$ was refined. The descent of symmetry introduces two independent anion sites into each four-atom anion ring. Refinement of site occupancy factors for the anion positions, with the constraint that each site remains fully occupied and that the overall stoichiometry is maintained, reveals that at room temperature, the Ge and $(\mathrm{S} / \mathrm{Te})$ anions are almost fully ordered over the sites within the anion rings. Representative final observed, calculated and difference neutron profiles are presented in Figure 3 and 4 respectively, whilst refined atomic parameters and interatomic distances and angles are provided as Supplementary Information. The degree of ordering is slightly greater for the sulphur-containing phase, in which only ca. $2 \%$ of Ge atoms reside at the $\mathrm{S}$ atom sites than for the telluride, where $c a .17 \%$ of Ge atoms are located in Te sites. This is consistent with our earlier work, which indicated that the degree of ordering decreases for larger anions [14]. In addition, in both compounds the $\mathrm{Co}(1)$ atoms are slightly displaced from the ideal $(0,0,1 / 4)$ position.

Data collected on heating $\mathrm{CoGe}_{1.5} \mathrm{~S}_{1.5}$ reveal that the superstructure reflections are present up to a temperature of $900{ }^{\circ} \mathrm{C}$, demonstrating that the rhombohedral symmetry is preserved. Refined site occupancy factors for the anions $(0.976(2)-0.988(8))$ show little deviation from their value at room temperature, indicating that near complete anion ordering persists to this temperature. As illustrated by Figure 5, the lattice parameters increase smoothly with increasing temperature up to $900{ }^{\circ} \mathrm{C}$. Bragg peaks are absent from the data collected at the next highest temperature of $950{ }^{\circ} \mathrm{C}$, which is consistent with melting of the sample having occurred. Powder neutron diffraction data collected on cooling (and laboratory powder X-ray diffraction data collected following subsequent recovery of the sample) indicate partial recovery of the skutterudite phase, albeit with a significant reduction in crystallinity, and the presence of a GeS impurity phase. Representative final observed, calculated and difference neutron profiles are presented in Figure 3, whilst refined atomic parameters 
obtained from data collected over the range $25 \leq \mathrm{T} /{ }^{\circ} \mathrm{C} \leq 900$ are provided as Supplementary Information.

By contrast, the powder neutron diffraction data collected for $\mathrm{CoGe}_{1.5} \mathrm{Te}_{1.5}$, (Figure 6) reveal that the intensity of the superstructure reflections decreases with increasing temperature until they disappear completely above $605{ }^{\circ} \mathrm{C}$. The data collected above this temperature can be indexed on the basis of a cubic unit cell $(\operatorname{Im} \overline{3})$. Rietveld refinements using data collected below $605{ }^{\circ} \mathrm{C}$ were carried out using a rhombohedral skutterudite model (space group $R \overline{3}$ ), whilst for data collected at higher temperatures, a cubic skutterudite model (space group $\operatorname{Im} \overline{3}$ ) was successfully used (Figure 4). Analysis of the powder diffraction data indicates that the lattice expands with increasing temperature (Figure 7); the lattice parameters exhibiting a linear temperature dependence in the cubic phase, with no evidence of anomalies at the transition temperature. The refined site occupancy factor for the anions (Figure 8) remains almost constant between room temperature $(0.83(1))$ and $555{ }^{\circ} \mathrm{C}(0.82(1))$. Above $555{ }^{\circ} \mathrm{C}$, the site occupancy factor decreases rapidly and reaches a value of 0.5 at $605{ }^{\circ} \mathrm{C}$. This indicates that the degree of anion ordering decreases as the phase transition is approached. There is then a statistical distribution of the anions over the available sites in the $\mathrm{Ge}_{2} \mathrm{Te}_{2}$ rings above the transition temperature. In the low-temperature rhombohedral phase, the two crystallographically independent $\mathrm{Ge}_{2} \mathrm{Te}_{2}$ rings have a diamond shape, with angles that deviate from $90^{\circ}$. The temperature dependence of the Ge-Te-Ge angle in the two crystallographically independent rings, denoted as $\theta_{1}$ and $\theta_{2}$, is illustrated in Figure 8. While these angles show little change from their room temperature value up to $555^{\circ} \mathrm{C}$, above this temperature $\theta_{1}$ and $\theta_{2}$ decrease rapidly and tend to $90^{\circ}$. In the high-temperature cubic skutterudite phase, there is only one crystallographically independent anion ring, which is rectangular with angles of $90^{\circ}$. Neutron and X-ray diffraction data collected after cooling the skutterudite to room temperature show the characteristic superstructure reflections of the rhombohedral phase, confirming the reversibility of the phase transition. 
Structural phase transitions are uncommon for skutterudites. A temperature-induced transformation occurs for $\operatorname{PrRu}_{4} \mathrm{P}_{12}$, which transforms from $\operatorname{Im} \overline{3}$ to $P m \overline{3}$ on cooling below the metal-to-insulator transition temperature, due to charge-density-wave ordering [25]. Investigations of the effect of pressure on the skutterudite structure have shown that $\mathrm{ReO}_{3}$, which adopts a skutterudite structure at $0.5 \mathrm{GPa}$, transforms to a monoclinic $\mathrm{MnF}_{3}$-related phase at $3 \mathrm{GPa}[26]$. The phase transition we report here is however, the first example of an order-disorder transition in a skutterudite. The contrasting behaviour of $\mathrm{CoGe}_{1.5} \mathrm{~S}_{1.5}$, for which no structural transition is observed, and $\mathrm{CoGe}_{1.5} \mathrm{Te}_{1.5}$, for which an order-disorder transition of the anions occurs, may be related to the differing bonding characteristics of elements drawn from different periods. Previous work has demonstrated that both the degree of anion ordering and of distortion of the four-membered anion rings decreases for ternary skutterudites containing elements from later periods [14]. This suggests that the difference between the free energies of formation of the ordered and disordered phases is reduced for skutterudites containing heavier chalcogens. Semiempirical calculations suggest that $\pi$ bonding within the $\mathrm{Ge}_{2} \mathrm{Q}_{2}$ rings and between the anions and the transition metal cation play an important role in determining the detailed structure of ternary skutterudites [8]. The strength of $\mathrm{p}_{\pi}-\mathrm{p}_{\pi}$ interactions decreases on descending a group, with the result that $\pi$ bonding involving maingroup anions from later periods, such as those found in $\mathrm{CoGe}_{1.5} \mathrm{Te}_{1.5}$, is reduced. This is consistent with the results of the Rietveld refinement which reveal a significant increase in the bond distances at $25{ }^{\circ} \mathrm{C}$ within the $\mathrm{Ge}_{2} \mathrm{Q}_{2}$ rings, on going from the sulphide (2.37(1)-2.55(1) $\AA$ ) to the telluride (2.73(1)-2.93(1) $\AA)$.

The thermoelectric properties for $\mathrm{CoGe}_{1.5} \mathrm{Te}_{1.5}$ upon heating are summarized in Figure 9. The electrical resistivity decreases with increasing temperature, and is consistent with semiconducting behaviour. The data exhibit Arrhenius behaviour over the temperature range $30 \leq T /{ }^{\circ} \mathrm{C} \leq 320$ (Figure 9), yielding an activation energy of $E_{\mathrm{g}}=61.3(1) \mathrm{meV}$ which is lower than the previously reported value $E_{\mathrm{g}}=0.16(1) \mathrm{eV}$ [9]. Measurements at higher 
temperatures indicate that the intrinsic band gap of $\mathrm{CoGe}_{1.5} \mathrm{Te}_{1.5}$ is $0.77 \mathrm{eV}$, [27] a value which is consistent with the calculated value of $0.51 \mathrm{eV}$ [28]. The band gap can also be estimated from the maximum value of the Seebeck coefficient $\left(\mathrm{S}_{\max }\right)$, using the expression, $\mathrm{S}_{\max }=\mathrm{E}_{\mathrm{g}} /\left(2 e \mathrm{~T}_{\max }\right)$ where $\mathrm{E}_{\mathrm{g}}$ is the band gap energy, $e$ is the electron charge and $\mathrm{T}_{\max }$ is the absolute temperature at which the maximum occurs.[29] This expression leads to an estimated value of the band gap of $0.33 \mathrm{eV}$ for our sample, which is also higher than that arising from the Arrhenius plot. This suggests that the activation energy determined for the temperature range $30 \leq T /{ }^{\circ} \mathrm{C} \leq 320$ is likely to correspond to the promotion of extrinsic electrons into the conduction band, and will therefore be dependent on the exact composition of each sample and the energy of the impurity levels in each case. Furthermore, the previously reported value of $E_{\mathrm{g}}=0.16(1) \mathrm{eV}$ [9] was determined using a cold-pressed and sintered pellet $(\sim 70 \%$ of theoretical density), in which the presence of grain boundaries will have resulted in an increased electrical resistivity. Seebeck coefficient measurements reveal $n$-type behaviour for the skutterudite, indicating that electrons are the dominant charge carriers. $|\mathrm{S}|$ exhibits a maximum value at $156{ }^{\circ} \mathrm{C}\left(\mathrm{S}=-382 \mu \mathrm{V} \mathrm{K}^{-1}\right)$. This differs from a previous report, in which a maximum value of $|\mathrm{S}|$ was determined at $87^{\circ} \mathrm{C}\left(\mathrm{S}=-540 \mu \mathrm{V} \mathrm{K} \mathrm{K}^{-1}\right)$ [27], suggesting that the electronic properties of this material are sensitively dependent on the level of doping. This view is supported by recent band structure calculations [20]. The decrease in the magnitude of the Seebeck coefficient above $156{ }^{\circ} \mathrm{C}$ would be consistent with an intrinsic conduction mechanism involving both electrons and holes. Notably, in the context of the diffraction study reported here, there is no abrupt change in $\mathrm{S}(\mathrm{T})$ through the phase transition.

On heating, the thermal conductivity decreases gradually from $2.9 \mathrm{~W} \mathrm{~m}^{-1} \mathrm{~K}^{-1}$ at $100{ }^{\circ} \mathrm{C}$ to $2.25 \mathrm{~W} \mathrm{~m}^{-1} \mathrm{~K}^{-1}$ at $400{ }^{\circ} \mathrm{C}$. These values are significantly lower than those of $\mathrm{CoSb}_{3}, \kappa(100$ $\left.{ }^{\circ} \mathrm{C}\right) \approx 7 \mathrm{~W} \mathrm{~m}^{-1} \mathrm{~K}^{-1}$ and are consistent with previous measurements of the thermal transport properties of $\mathrm{CoGe}_{1.5} \mathrm{Te}_{1.5}$ [18]. The electronic contribution, $\kappa_{\mathrm{e}}$, to the thermal conductivity, estimated from the Wiedemann-Franz law $\left(\kappa_{\mathrm{e}}=L T / \rho\right.$ where $L=1.510^{-8} \mathrm{~W} \Omega \mathrm{K}^{-2}$ for a non- 
degenerate semiconductor),[30] is small: increasing from $c a .0 .14 \%$ at $100{ }^{\circ} \mathrm{C}$ to $9.7 \%$ at 650 ${ }^{\circ} \mathrm{C}$. As illustrated by Fig. 9, the thermal conductivity of $\mathrm{CoGe}_{1.5} \mathrm{Te}_{1.5}$ starts to increase above $400{ }^{\circ} \mathrm{C}$, reaching a maximum value of $3.4 \mathrm{~W} \mathrm{~m}^{-1} \mathrm{~K}^{-1}$ at $630{ }^{\circ} \mathrm{C}$. We previously suggested that anion ordering would affect the phonon dispersion curves and the corresponding phonon density of states (DOS), as a consequence of the lower crystal symmetry of the ordered skutterudite when compared with the disordered structure ( $R \overline{3}$ vs. $\operatorname{Im} \overline{3})$ [14]. On this basis, a significant change in the thermal conductivity of $\mathrm{CoGe}_{1.5} \mathrm{Te}_{1.5}$ would be expected at the phase-transition temperature. Recent calculations of phonon dispersion led to the conclusion that dispersion alone cannot explain the lower thermal conductivities of ordered skutterudites, when compared with binary phases such as $\mathrm{CoSb}_{3}[20]$. This study suggested that the phonon scattering mechanism in the family of ternary phases $\mathrm{AB}_{1.5} \mathrm{Q}_{1.5}$ is very different to phonon scattering in $\mathrm{CoSb}_{3}$, due to the different nature of the bonding [20]. Taking this into account, disordered ternary skutterudites would still exhibit lower thermal conductivities than binary skutterudites, due to the greater ionicity of the bonding together with the presence of mass fluctuations at the anion site. This would lead us to predict a reduction in thermal conductivity at the order-disorder transition. Whilst our data suggests that the structural phase transition results in a significant increase in thermal conductivity, detailed investigation indicated that evaporation of tellurium occurs at the highest temperatures at which thermal transport measurements are made. No comparable volatilization of tellurium was observed at high temperatures during the collection of powder neutron diffraction data. The origin of this difference lies in the sample for thermal transport property measurements being located in a volume that is large compared with that of the sealed silica ampoule in which the powder for neutron diffraction measurements was contained. The presence of temperature gradients in the larger volume leads to condensation of tellurium on the colder areas of the sample space, resulting in irreversible removal of tellurium from the sample. The vaporisation of tellurium was confirmed by TGA measurements in a flowing $\mathrm{N}_{2}$ atmosphere (Supplementary 
Information), which indicate that $\mathrm{CoGe}_{1.5} \mathrm{Te}_{1.5}$ begins to lose weight at ca. $500{ }^{\circ} \mathrm{C}$. Volatilization of tellurium leads to the formation of CoGe on the pellet's surface, as verified by powder X-ray diffraction on the sample following completion of the measurements. Since CoGe is metallic $\left(\rho\left(27^{\circ} \mathrm{C}\right)=65 \mu \Omega \mathrm{cm}\right)[31]$ this is likely to be the cause of the observed irreversibility of the $\rho(\mathrm{T})$ and $\mathrm{S}(\mathrm{T})$ behaviour and the very low values of each property following cooling to room temperature (Figure S4). On heating, the maximum in power factor $\left(\mathrm{S}^{2} / \rho\right)$ is observed at $312{ }^{\circ} \mathrm{C}\left(0.215 \mathrm{~mW} \mathrm{~m}^{-1} \mathrm{~K}^{-2}\right)$, which is significantly lower than the power factor of antimony-based skutterudites [32]. This is primarily due to the larger electrical resistivity of $\mathrm{CoGe}_{1.5} \mathrm{Te}_{1.5}$. The thermoelectric figure of merit for $\mathrm{CoGe}_{1.5} \mathrm{Te}_{1.5}$ reaches a maximum value of $Z T=0.051$ at $400{ }^{\circ} \mathrm{C}$ (Figure 9(d)).

\section{Conclusions}

Variable temperature neutron diffraction experiments reveal that the complete anion ordering of $\mathrm{CoGe}_{1.5} \mathrm{~S}_{1.5}$ is retained to the temperature at which melting occurs $\left(900 \leq \mathrm{T} /{ }^{\circ} \mathrm{C} \leq\right.$ 950). By contrast, $\mathrm{CoGe}_{1.5} \mathrm{Te}_{1.5}$ undergoes an order-disorder transition at $c a .600{ }^{\circ} \mathrm{C}$. The difference in the behaviour of the sulphur- and tellurium-containing phases may be related to the stronger $\mathrm{p}_{\pi}-\mathrm{p}_{\pi}$ interactions of the lighter chalcogen within $\mathrm{Ge}_{2} \mathrm{Q}_{2}$ rings. The effect of this transition on the thermoelectric properties of $\mathrm{CoGe}_{1.5} \mathrm{Te}_{1.5}$ is complicated by the irreversible loss of tellurium at elevated temperatures during the course of physical property measurements. It would be desirable to carry out such measurements with retention of sample composition, in order to investigate further the possible effect of the phase transition on the thermal transport behaviour.

\section{Acknowledgements}

The authors wish to thank the UK EPSRC for financial support (EP/H050396) and the STFC for access to neutron scattering facilities. 


\section{Supplementary Information}

Rietveld plots from X-ray data for $\operatorname{CoGe}_{1.5} \mathrm{Q}_{1.5}(\mathrm{Q}=\mathrm{Ge}, \mathrm{Te})$, powder X-ray diffraction data for $\mathrm{CoGe}_{1.5} \mathrm{Te}_{1.5}$ after hot pressing, electrical resistivity and Seebeck coefficient measurements for $\mathrm{CoGe}_{1.5} \mathrm{Te}_{1.5}$ upon cooling, TGA diagram of $\mathrm{CoGe}_{1.5} \mathrm{Te}_{1.5}$, tables of atomic positions and $\mathrm{Co}-\mathrm{Ge} / \mathrm{Q}$ distances.

\section{References}

[1] J. R. Sootsman, D. Y. Chung, M. G. Kanatzidis, Angew. Chem. Int. Ed. 48 (2009) 86168639.

[2] A. V. Shevelkov, Russ. Chem. Rev. 77 (2008) 1-19

[3] R. H. Mitchell, "Perovskites: Modern and Ancient", Almaz Press, Ontario, Canada (2002).

[4] W. Jeitschko, D. Braun, Acta Crystallogr. Sect. B 33 (1977) 3401-3406.

[5] G. S. Nolas, D. T. Morelli, T. M. Tritt, Annu. Rev. Mater. 29 (1999) 89-116.

[6] R. Korenstein, S. Soled, A. Wold, G. Collin, Inorg. Chem. 16 (1977) 2344-2346.

[7] A. Lyons, R. P. Gruska, C. Case, S. N. Subbarao, A. Wold, Mat. Res. Bul. 13 (1978) $125-$ 128.

[8] M. Partik, C. Kringe, H. D. Lutz, Z. Kristallogr. 211 (1996) 304-312.

[9] P. Vaqueiro, G. G. Sobany, A. V. Powell, K. S. Knight, J. Solid State Chem. 179 (2006) 2047-2053.

[10] J. W. G. Bos, R. J. Cava, Solid State Commun. 141 (2007) 38-41.

[11] F. Laufek, J. Návrátil, V. Goliáš, Powder Diffr. 23 (2008) 15-19.

[12] P. Vaqueiro, G. G. Sobany, M. Stindl, J. Solid State Chem. 181 (2008) 768-776.

[13] F. Laufek, J. Návrátil, J. Plášil, T. Plecháček, Č. Drašar, J. Alloys Compd. 479 (2009) 102-106.

[14] P. Vaqueiro, G. G. Sobany, A. V. Powell, Dalton Trans. 39 (2010) 1020-1026.

[15] Y. Liang, W. Schnelle, N. Oeschler, S. Budnyk, Y. Grin, Z. Kristallogr. 226 (2011) 6267.

[16] G.S. Nolas, J. Yang, R.W. Ertenberg, Phys. Rev. B 68 (2003) 193206.

[17] Y. Nagamoto, K. Tanaka, T. Koyanagi, Proceedings of the $16^{\text {th }}$ International Conference on Thermoelectrics (1997) 330-333.

[18] P. Vaqueiro, G. G. Sobany, in Thermoelectric Power Generation, edited by T.P. Hogan, J. Yang, R. Funahashi and T. Tritt, Mater. Res. Soc. Symp. Proc. 1044 (2008) 185-190. 
[19] J. Návrátil, T. Plecháček, L. Beneš, Č. Drašar, F. Laufek, J. Electron. Mater. 39 (2010) $1880-1884$.

[20] D. Volja, B. Kozinsky, A. Li, D. Wee, N. Marzari, M. Fornari Phys. Rev. B 85 (2012) 245211.

[21] Details of the Mantid High-Performance Computing Project may be found at http://www.mantidproject.org

[22] A.C. Larson, R.B. von Dreele, General Structure Analysis System, Los Alamos Laboratory, [Report LAUR 85-748], 1994.

[23] P. S. Gaal and S. P. Apostolescu, US patent No. US 6,375,349 (2002).

[24] M.-A. Thermitus and P. S. Gaal, Proceedings of the $24^{\text {th }}$ International Thermal Conductivity Conference, Eds. C. Uher and D. Morelli, Technomic Publishing Co., Lancaster, p. $340(2000)$.

[25] C. H. Lee, H. Matsuhata, H. Yamaguchi, C. Sekine, K. Kihou, T. Suzuki, T. Noro, I. Shirotani Phys. Rev. B 70 (2004) 153105.

[26] J.-E. Jorgensen, J. S. Olsen, L. Gerward, J. Appl. Cryst. 33 (2000) 279-284.

[27] J. Návrátil, T. Plecháček, L. Beneš, M. Vlček, J. Optoel. Adv. Mat. 6 (2004) 787-790.

[28] D.Volja, M. Fornari, B.Kozinsky, N. Marzari, in Materials and Devices for Thermal-toElectric Energy Conversion, ed. J. Yang, G. S. Nolas, K. Koumoto, Y. Grin, Mater. Res. Soc. Symp. Proc. Volume 1166, Warrendale, PA, 2009, 1166-N05-04.

[29] H.J. Goldsmid, J.W.Sharp, J. Electron. Mater. 28 (1999) 869-872.

[30] T.M. Tritt, “Thermal conductivity. Theory, Properties and Applications.” Springer, New York, USA (2004).

[31] Ch. Krontiras, S. N. Georga, S. Sakkopoulos, E. Vitoratos, J. Salmi J. Phys.: Condens. Matter. 2 (1990) 3323-3328.

[32] X. Shi, H. Kong, C.-P. Li, C. Uher, J. Yang, J. R. Salvador, H. Wang, L. Chen, W. Zhang Appl. Phys. Lett. 92 (2008) 182101. 


\section{Figure Captions}

\begin{tabular}{|c|c|}
\hline Figure 1 & $\begin{array}{l}\text { (a) Polyhedral representation of skutterudite structure, } \mathrm{MX}_{3}(\mathrm{M} \\
=\mathrm{Co}, \mathrm{Rh}, \mathrm{Ir} \text { and } \mathrm{X}=\mathrm{P}, \mathrm{As}, \mathrm{Pb}) \text {; and (b) ball-and-stick } \\
\text { representation of the } \mathrm{MX}_{3} \text { structure, showing the four- } \\
\text { membered } \mathrm{X}_{4} \text { rings. Key: } \mathrm{X} \text {, white (orange) circles; } \mathrm{M} \text {, grey } \\
\text { (blue) circles. In (a), } \mathrm{M} \text { atoms are located at the centre of the } \\
\text { octahedra. }\end{array}$ \\
\hline Figure 2 & $\begin{array}{l}\text { The crystal structure of the ordered skutterudite } \mathrm{CoGe}_{1.5} \mathrm{Te}_{1.5} \text {. } \\
\text { Key: Co, grey (blue) circles; Ge, white (red) circles; Te black } \\
\text { (yellow) circles. }\end{array}$ \\
\hline Figure 3 & $\begin{array}{l}\text { Final observed (crosses), calculated (solid line) and difference } \\
\text { (full lower line) profiles from Rietveld refinements for } \\
\mathrm{CoGe}_{1.5} \mathrm{~S}_{1.5} \text { using neutron diffraction data from (a) the } \\
\text { backscattering bank and (b) the } 90^{\circ} \text { bank at } 25{ }^{\circ} \mathrm{C} \text {, and (c) the } \\
\text { backscattering bank and (d) the } 90^{\circ} \text { bank at } 900{ }^{\circ} \mathrm{C} \text {. }\end{array}$ \\
\hline Figure 4 & $\begin{array}{l}\text { Final observed (crosses), calculated (solid line) and difference } \\
\text { (full lower line) profiles from Rietveld refinements for } \\
\mathrm{CoGe}_{1.5} \mathrm{Te}_{1.5} \text { using neutron diffraction data from (a) the } \\
\text { backscattering bank and (b) the } 90^{\circ} \text { bank at } 25^{\circ} \mathrm{C} \text {, and (c) the } \\
\text { backscattering bank and (d) the } 90^{\circ} \text { bank at } 665^{\circ} \mathrm{C} \text {. Superlattice } \\
\text { reflections are indicated by arrows. }\end{array}$ \\
\hline Figure 5 & $\begin{array}{l}\text { Temperature dependence of the unit-cell parameters (hexagonal } \\
\text { setting) of } \mathrm{CoGe}_{1.5} \mathrm{~S}_{1.5} \text {. Error bars lie within the points. }\end{array}$ \\
\hline Figure 6 & $\begin{array}{l}\text { Powder neutron diffraction data as a function of temperature for } \\
\mathrm{CoGe}_{1.5} \mathrm{Te}_{1.5} \text { from the high-resolution backscattering detector } \\
\text { bank illustrating the disappearance of the superstructure } \\
\text { reflections (marked with }{ }^{*} \text { ) on passing through the phase } \\
\text { transition. }\end{array}$ \\
\hline Figure 7 & $\begin{array}{l}\text { Temperature dependence of the unit-cell parameters of } \\
\mathrm{CoGe}_{1.5} \mathrm{Te}_{1.5} \text {. Solid points denote parameters for the } \\
\text { rhombohedral modification. Open points denote parameters for } \\
\text { the cubic modification converted to the equivalent } \\
\text { rhombohedral unit cell to facilitate comparison. Error bars lie }\end{array}$ \\
\hline
\end{tabular}




\begin{tabular}{|l|l|}
\hline Figure 8 & within the points. \\
& $\begin{array}{l}\text { The variation with temperature in } \mathrm{CoGe}_{1.5} \mathrm{Te}_{1.5} \text { of (a) the } \\
\text { distortion angles } \theta_{1} \text { and } \theta_{2} \text { within the } \mathrm{Ge}_{2} \mathrm{Te}_{2} \text { rings, defined as } \\
\mathrm{Ge}(1)-\mathrm{Te}(3)-\mathrm{Ge}(1) \text { and } \mathrm{Ge}(2)-\mathrm{Te}(4)-\mathrm{Ge}(2) \text { respectively; and (b) } \\
\text { the site occupancy factor (SOF) of the anion sites, where SOF }= \\
1.0 \text { corresponds to complete ordering of } \mathrm{Ge} \text { and Te and SOF }= \\
0.5 \text { to a fully disordered structure. Open points refer to the } \\
\text { cubic modification }\left(\theta_{1}=\theta_{2}=90^{\circ}\right) \text { and solid points to the } \\
\text { rhombohedral phase. }\end{array}$ \\
\hline Figure 9 & $\begin{array}{l}\text { Thermoelectric properties for } \mathrm{CoGe}{ }_{1.5} \mathrm{Te}_{1.5} \quad \text { (a) electrical } \\
\text { resistivity with the inset showing the } \ln \rho-T^{-1} \text { plot and the linear } \\
\text { fit over the temperature range } 30 \leq T /{ }^{\circ} \mathrm{C} \leq 320 \text { (b) Seebeck } \\
\text { coefficient, (c) power factor, (d) thermal conductivity and (e) } \\
\text { thermoelectric figure of merit }(Z T) .\end{array}$ \\
\hline
\end{tabular}


Figure 1(a)

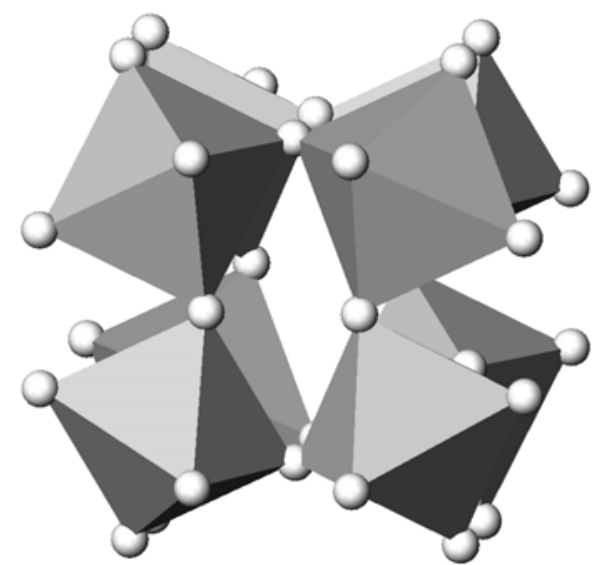


Figure 1(b)

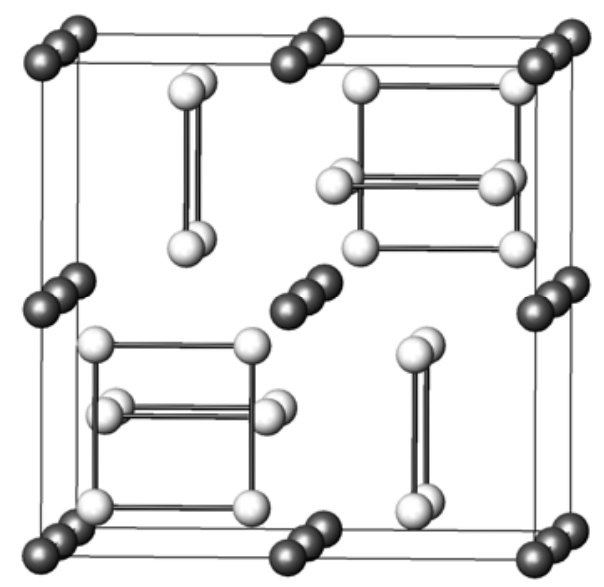


Figure 2

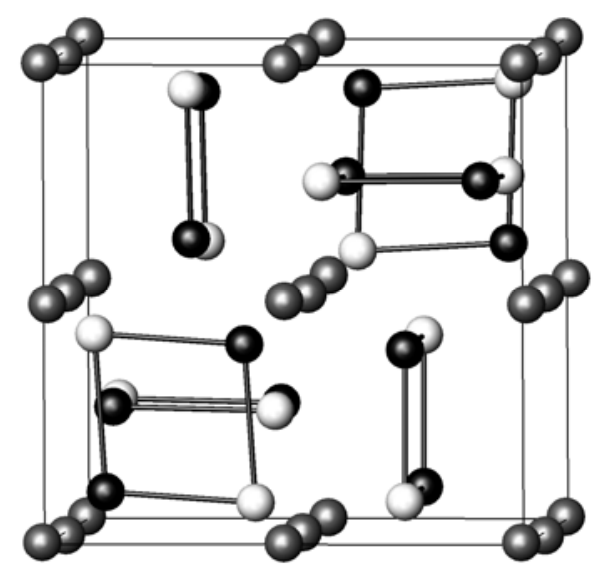


Figure 3
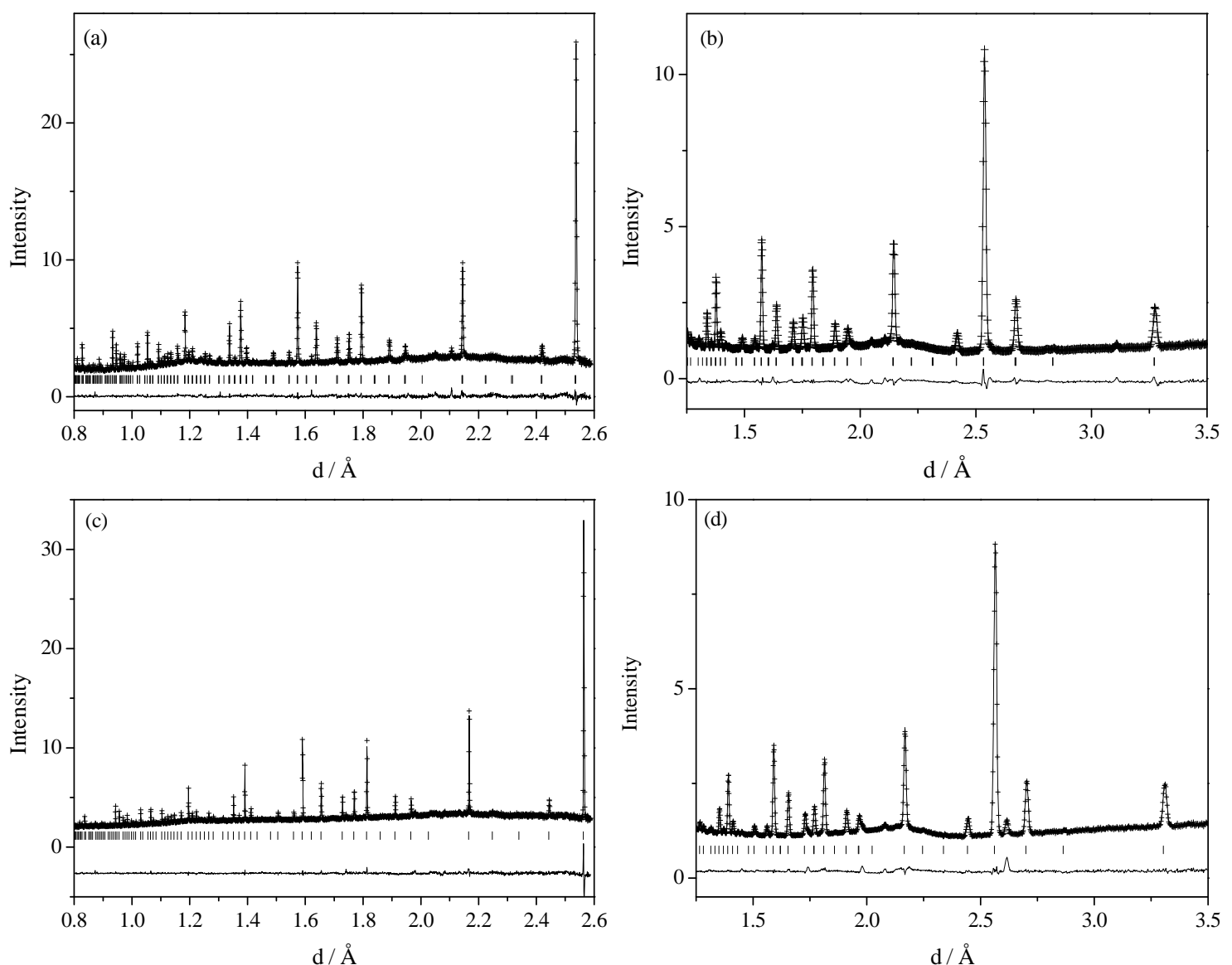
Figure 4
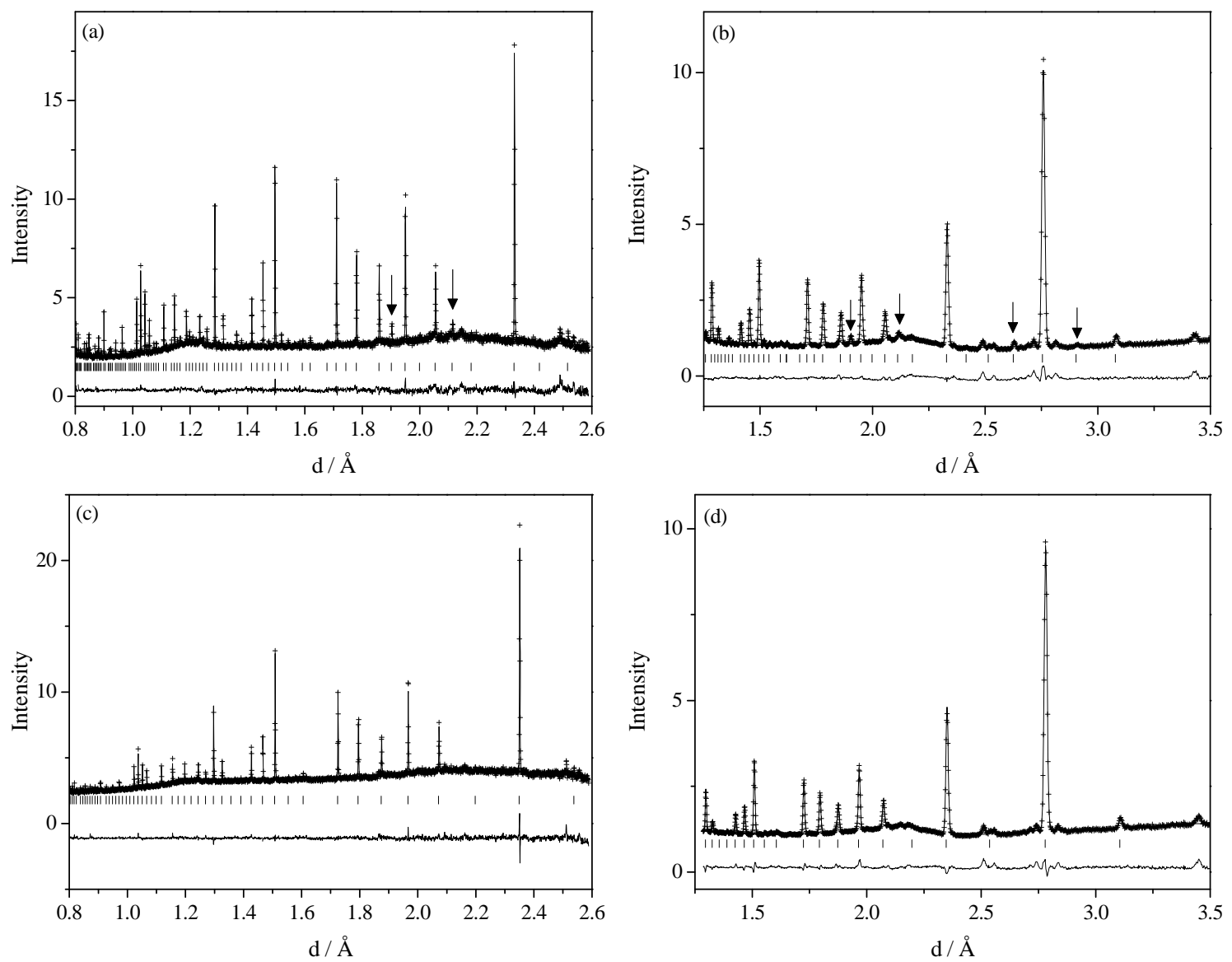
Figure 5

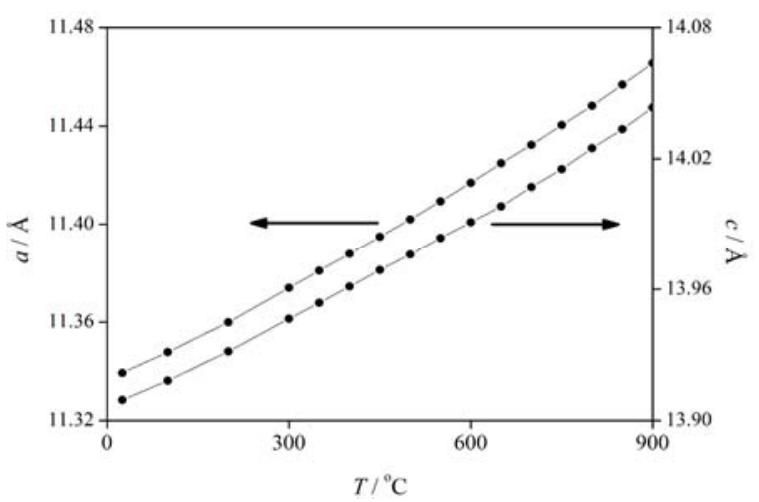


Figure 6

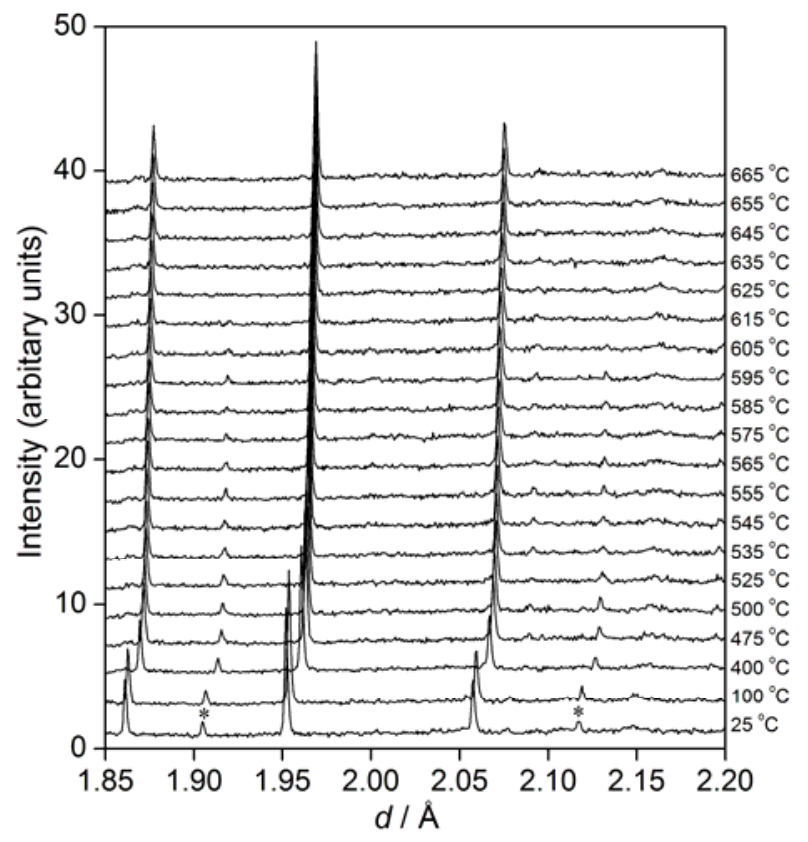


Figure 7

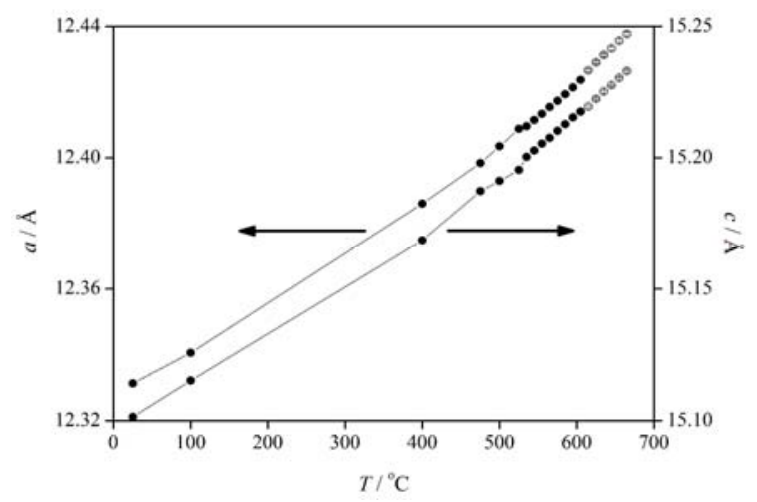


Figure 8

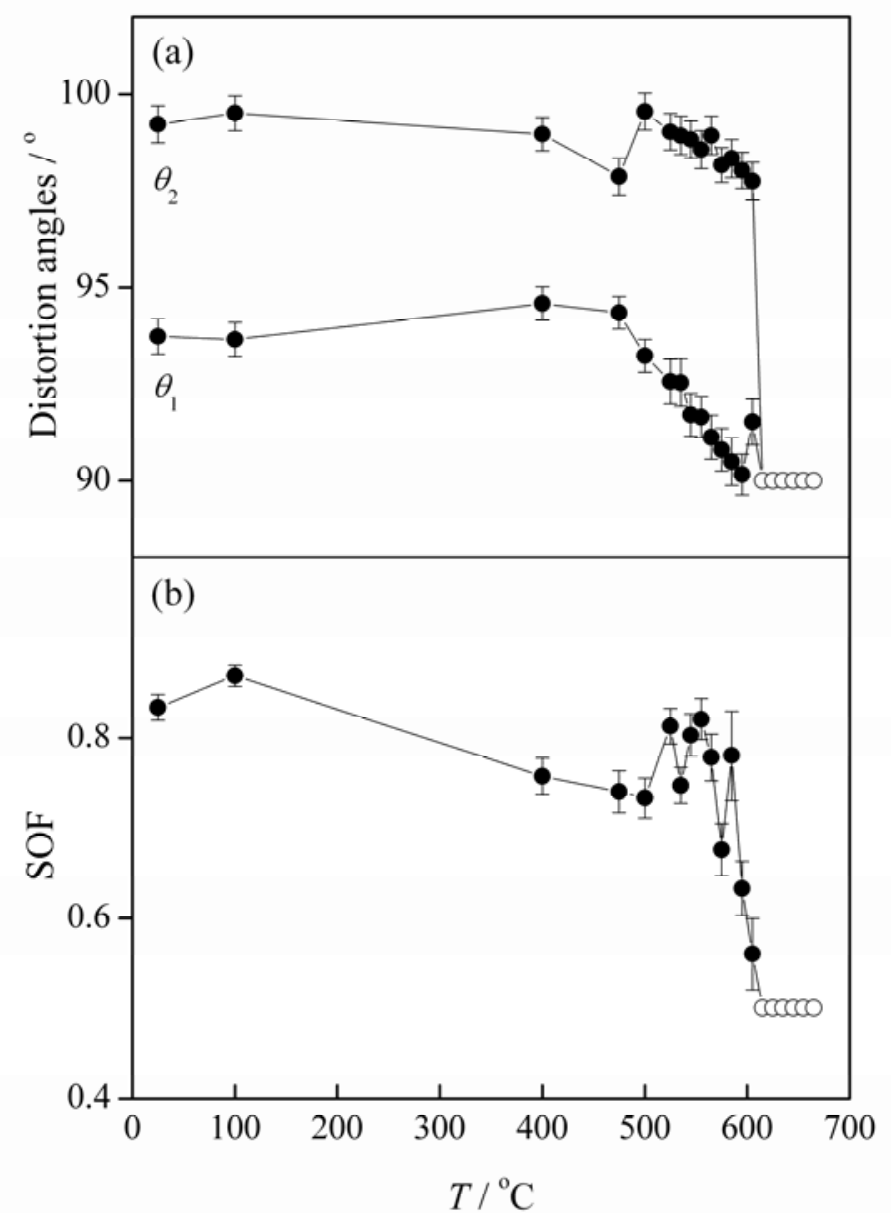


Figure 9
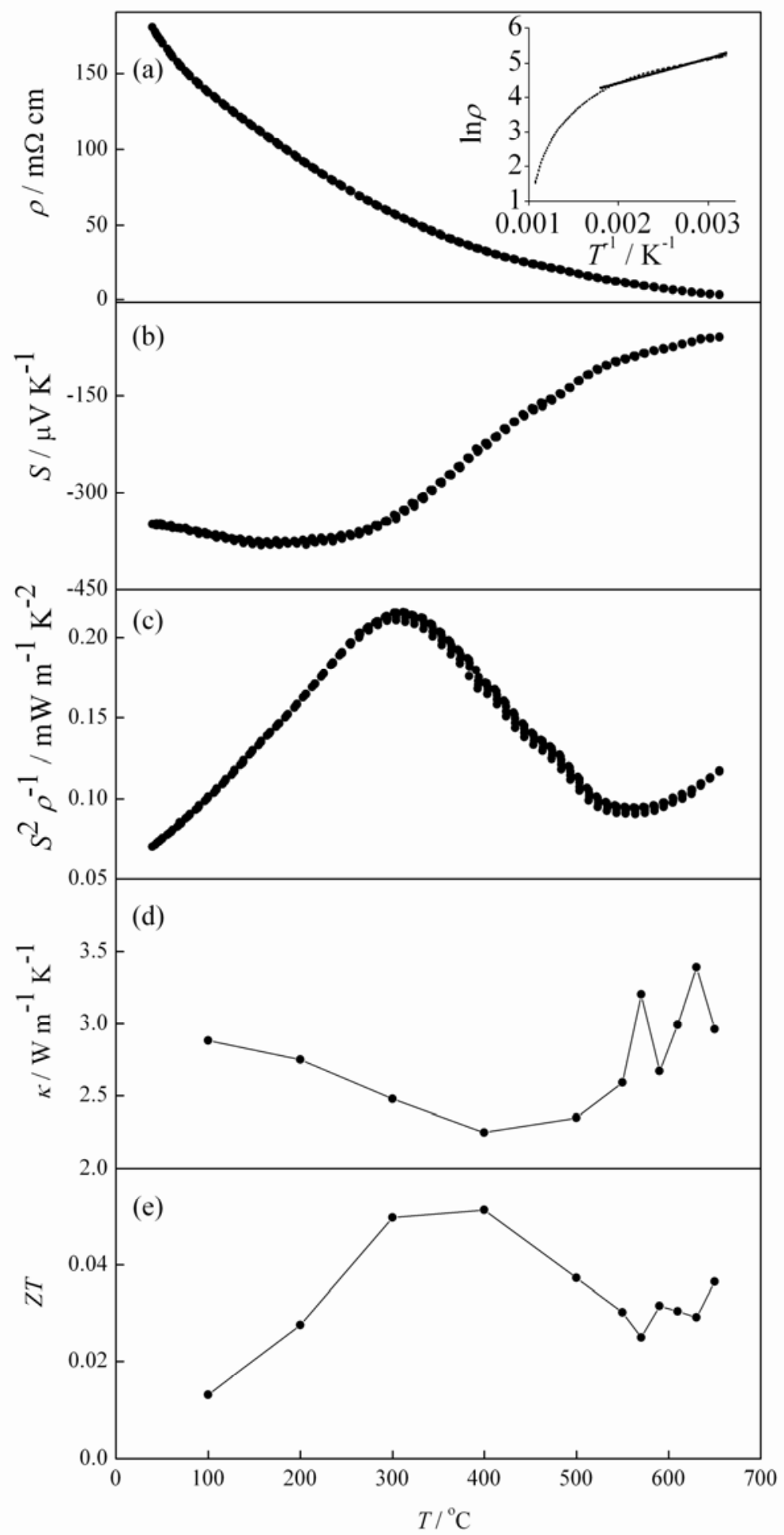